\title{
Sex Differences in Genetic and Environmental Influences on Educational Attainment and Income
}

\author{
Ragnhild E. Ørstavik, ${ }^{1}$ Nikolai Czajkowski, ${ }^{1,2}$ Espen Røysamb, ${ }^{1,2}$ Gun Peggy Knudsen, ${ }^{1}$ Kristian Tambs, ${ }^{1}$ \\ and Ted Reichborn-Kjennerud ${ }^{1,3,4}$ \\ ${ }^{1}$ Department of Mental Health, Norwegian Institute of Public Health, Oslo, Norway \\ ${ }^{2}$ Institute of Psychology, University of Oslo, Oslo, Norway \\ ${ }^{3}$ Institute of Psychiatry, University of Oslo, Oslo, Norway \\ ${ }^{4}$ Department of Epidemiology, Columbia University, New York, NY, USA
}

\begin{abstract}
In many Western countries, women now reach educational levels comparable to men, although their income remains considerably lower. For the past decades, it has become increasingly clear that these measures of socio-economic status are influenced by genetic as well as environmental factors. Less is known about the relationship between education and income, and sex differences. The aim of this study was to explore genetic and environmental factors influencing education and income in a large cohort of young Norwegian twins, with special emphasis on gender differences. National register data on educational level and income were obtained for 7,710 twins (aged 29-41 years). Bivariate Cholesky models were applied to estimate qualitative and quantitative gender differences in genetic and environmental influences, the relative contribution of genetic and environmental factors to the correlation between education and income, and genetic correlations within and between sexes and phenotypes. The phenotypic correlation between educational level and income was 0.34 (0.32-0.39) for men and $0.45(0.43-0.48)$ for women. An ACE model with both qualitative and quantitative sex differences fitted the data best. The genetic correlation between men and women $\left(r_{g}\right)$ was $0.66(0.22-1.00)$ for educational attainment and $0.38(0.01-0.75)$ for income, and between the two phenotypes $0.31(0.08-0.52)$ for men and $0.72(0.64-0.85)$ for women. Our results imply that, in relatively egalitarian societies with state-supported access to higher education and political awareness of gender equality, genetic factors may play an important role in explaining sex differences in the relationship between education and income.
\end{abstract}

Keywords: twin studies, education, income, socio-economic status, sex differences

In Norway, as well as most other developed countries, a growing proportion of men and women obtain college or university degrees, and the share of women with higher education is increasing at a quicker rate than the share of men (Hirsch et al., 2010). In 2008, 29\% of Norwegian women and $25 \%$ of men had higher education. The female majority in higher education is not unique to Norway, but applies to most $\mathrm{EU}$ countries, including the new member states (Hirsch et al., 2010).

Labor force participation for women is high in Norway, and the gap between women's and men's participation is small compared with other countries (Hirsch et al., 2010). Since the 1980s, women aged $25-40$ years in particular have been more active in the labor market. But in contrast to educational attainment, there are still large gender gaps in economic achievement. This can partly be explained by more women than men working part time (in 2008, 43\% of Norwegian women and 13\% of Norwegian men worked part time; Hirsch et al., 2010), but also by the fact that the returns to education vary strongly between professions. According to EU reports (European Commission, 2013), average gross hourly earnings for women are approximately $84 \%$ of that for men. In Norway, the raw wage gap (i.e., annual income independent of, e.g., part-time employment) was $32.5 \%$ in 2003 , while the adjusted wage gap was $15.5 \%$ and thus comparable to EU averages (Skrede, 2010).

Norway is a relatively egalitarian society with regard to socio-economic status. Still, social inequalities in mortality seem to have increased during the past decades (Rognerud \& Zahl, 2006). Both educational attainment and economic

RECEIVED 16 February 2014; ACCEPTED 12 August 2014.

ADDRESS FOR CORRESPONDENCE: Ragnhild Elise Ørstavik, Norwegian Institute of Public Health, PO Box 4404, Nydalen N-0403, Oslo, Norway. E-mail: reor@fhi.no 
achievement are associated with mental and physical health, wellbeing, and longevity (Adler \& Ostrove, 1999). The relationship between educational achievement and health, and to what degree economic factors mediate this association, has been studied extensively. According to recent studies from the United States, it seems that both the raw effect of education on health, and the mediating effect of income, varies both over age and between cohorts (Lynch, 2006). The latter might be especially strong during midlife, but it also significant in young adults (Lynch, 2006). From a public health perspective, it is, thus, important to study factors influencing both educational and economic achievement, and the underlying factors explaining individual variations in these constructs.

Educational attainment is to a large degree dependent on familial factors (Ermisch \& Francesconi, 2001; Saeter, 2009). Intergeneration mobility in income has increased in the past decades, and seems to be especially strong in Scandinavia (Bratberg et al., 2005). Still, sibling correlations are significant, and seem to be more important than neighborhood and other societal variables (Bjorklund et al., 2002; Lindahl, 2011).

For the past three decades, several studies using genetically informative designs have documented that familial transmission of educational attainment (years of schooling) is both genetic and environmental in nature (Heath et al., 1985; Johnson et al., 2010; Szanton et al., 2009; Tambs et al., 1989). Simultaneously, access to higher education and mean levels of schooling obtained have increased substantially during the past 50 years. Today, the great majority of the population in OECD countries completes some sort of secondary education (OECD, 2011). In a study from Heath et al. (1985), the authors compared three birth cohorts from 1915 to 1960. They found that for males, the relative influence of genetic versus shared environmental factors increased with time, so that genetic factors were more important in cohorts born after, than before World War II. For females, however, the relative importance of these factors changed very little, and in the youngest cohort, shared environmental factors still contributed substantially to educational achievement. In a subsequent article, Tambs et al. (1989) studied four birth cohorts of male twins and found a large and significant decrease in the influence of shared environmental factors on educational attainment between those born before and those born after World War II, and a corresponding increase in genetic influence. In a study from Australia, however, there was no evidence for secular trends or sex differences (Le et al., 2010; Miller et al., 1999). A recent meta-analysis of genetic and environmental influences on educational attainment in 15 samples from different countries clearly demonstrates, however, that the heritability of educational attainment and the influence of family environment varies substantially between nations, and is dependent on generation and sex - with heritability generally being higher in men and in those born in the second half of the 20th century (Branigan et al., 2013). However, few studies have included opposite sex twins and thus been able to explore the issue of gender differences.

Previous studies on genetic and environmental influences on economic achievement have emerged from the field of economics, including studies focusing on explaining the 'gender pay gap', (i.e., the average difference between men's and women's hourly earnings; Bonjour et al., 2002; Miller et al., 1996, 2006) and on lifetime earnings and wealth (for a comprehensive review of genoeconomic studies, see Benjamin et al., 2012). The former is interesting from an individual perspective: while statistics on average gross hourly earnings for women versus men are important to elaborate gender discrimination in the labor force (equal pay for equal work), absolute income is influenced also by choice of occupation, and a subject's willingness to work part time, or abstain from paid work altogether. All might be influenced by societal (gender stereotypy, expectations from the community) and individual (i.e., personality) factors. Results from previous studies indicate a small to moderate heritability of income, with higher estimates for men than for women (Benjamin et al., 2012; Björklund \& Jäntti, 2009). So far, few classical twin studies have been conducted, especially including opposite sex twins, and thus the possibility to explore qualitative gender differences (Benjamin et al., 2012; Björklund \& Jäntti, 2009).

With regard to a causal relationship between education and income, previous research on a UK female twin sample indicates that this might be confounded by genetic factors as well as family background and ability scores (Bonjour et al., 2002). In light of the above discussed discrepancy in the past decades' development of educational and income levels for men and women (equal levels of education but still large discrepancies in income), it is thus of great interest to explore to what extent different genetic and environmental factors influence the two measures of socio-economic status, and whether the magnitude of genetic and environmental influence differ between genders. If genetic factors influencing educational attainment differ significantly from those influencing income, this might increase our understanding of the discrepancies observed in how increased education does not necessarily lead to increased economic achievement, especially for women. If the same is true for environmental factors, this might shed important light on possible interventions - again with the gender perspective in mind. To the best of our knowledge, no previous studies have used the bivariate twin modeling approach to answer these questions.

The aim of the current study was to estimate the relative contributions of genetic and environmental factors to educational levels and income in a cohort of young adult Norwegian twins. We particularly wanted to explore the bivariate relationship between the two outcomes. As our sample included opposite sex twins, we were also able to fully explore how genetic and environmental factors 
influencing education and income might be dependent on sex.

\section{Materials and Methods}

\section{Sample}

Data for the current analyses came from the Norwegian Institute of Public Health Twin Panel (NIPHTP). This database includes twins identified through information from the National Medical Birth Registry, established January 1,1967 , which receives mandatory notification of all live- and stillbirths of at least 16 weeks gestation. Two questionnaire studies have been conducted to obtain data on zygosity, demographics and somatic and mental health: in 1992 (Q1 - twins born 1967-1974) and in 1998 (Q2 — twins born 1967-1979; Harris et al., 2006). Altogether, 12,700 twins received the second questionnaire, and 8,045 responded (response rate 63\%). Female sex, monozygosity, and higher education predicted participation in Q2 (Tambs et al., 2009). When linking questionnaire data to public registries, we aimed to include twins who took part in the second questionnaire, as well as 20 subjects from the same cohort who subsequently agreed to participate in other studies where zygosity information was obtained. Of these 8,065 eligible participants, 315 had resigned from the NIPHTP since 1998, 38 declined to have their questionnaire data linked to public registries, and for one twin, previously obtained data and agreement forms were insufficient to be included. Thus, our final sample included 7,710 subjects.

Zygosity was initially determined using questionnaire items previously shown to classify correctly more than $97 \%$ of the twin pairs (Magnus et al., 1983), and molecular markers for a subgroup of the sample, based on genotyping 24 microsatellite markers. The discrepancy between classification based on the questionnaire and DNA markers implied an expected misclassification of less than $2 \%$ for the whole sample (Tambs et al., 2009). The NIPHTP and the Norwegian Twin Registry is described thoroughly elsewhere (Harris et al., 2006; Nilsen, Brandt et al., 2012; Nilsen, Knudsen et al., 2012).

Approval for the current study was received from the Regional Ethical Committee.

\section{Measures}

The main outcome variables used in the present study were registry-based information about education and income in 2008.

Using the unique national identification numbers issued to all Norwegians at birth, data obtained from the sample described above were linked to registries at Statistics Norway: The Norwegian National Education Database (NUDB) and the Income Register. NUDB includes individually based statistics on education since 1970, including annually completed education (graduates). The income statistics have been produced annually from 1993. By linking income data from the tax returns to income data from other administrative registers (including, among others, tax returns, End of the Year Certificate Register [unemployment benefits, various tax-free transfers], The Norwegian Ministry of Health and Care Services), the Income Register has comprehensive statistics covering most of the population's cash income. For the purpose of the current study, which focuses on educational attainment and earning, we applied the variable 'work related income'. This variable includes income from employees and the self-employed (excluding benefits and capital income). In the twin analyses, education was measured using eight categories, from 0 (no education) and 1 (compulsory education only) to 7 (doctoral degree), and income was included in the analyses as eight categories based on percentiles. The upper limit for the lowest category was approximately $20,000 €$, the lower limit for the highest category was approximately $74,000 €$.

\section{Statistics}

In the classical twin design, variation in traits is decomposed into the additive genetic (A), shared environment (C), and non-shared (unique) environment (E) latent factors. As monozygotic (MZ) twins share all their genetic material, and dizygotic (DZ) twins share on average half of their segregating genes, $A$ would tend to make $M Z$ twins correlate twice as high as DZ twins. C is defined as environmental factors that contribute to similarity between twins, and is further assumed to have an equal effect on $\mathrm{MZ}$ and DZ twins. E is by definition not shared between twins in a pair, and hence does not contribute to twin similarity. E also contains the measurement error that is inherent in the total observed variance of the specified model. The influence of each of these factors on the variables can be estimated using structural equation modelling. For the twin models, liability threshold models were fitted using the raw data option in OpenMx (Boker et al., 2011). Under minimum regularity conditions, the difference in -2 times log likelihood ( $\Delta-2 \mathrm{LL})$ is asymptotically chi-squared distributed, which allows testing for significant deterioration in chi-squared for nested submodels. If the difference in chi-squared is non-significant, the more restricted model is preferred over the less restricted model. Akaike Information Criterion (AIC) (Akaike, 1987), calculated as $\chi^{2}-2 d f$ was used in order to select the best fitting and most parsimonious model. Preferred models are those with the lowest AIC-value.

With data on multiple phenotypes, it is possible to make use of the additional information in the cross-twin crosstrait correlation to determine the degree of genetic and environmental overlap between the variables. In the bivariate analyses, we examined to what extent A, C and E factors accounted for the covariance between education and income, applying the Cholesky decomposition (Neale \& Cardon, 1992). In this study, we wanted to pay particular attention to possible sex differences. Quantitative sex 


\section{TABLE 1}

Polychoric Correlations Between Education and Income

\begin{tabular}{lllll}
\hline & & \multicolumn{2}{c}{ Cross-twin correlation } & \\
\cline { 3 - 4 } Zygosity $(n)$ & Within-twin correlation Education/Income & Educational level & Income & Cross-twin cross-trait correlation \\
\hline MZM $(1,194)$ & $0.35(0.29-0.41)$ & $0.75(0.70-0.79)$ & $0.55(0.48-0.62)$ & $0.34(0.28-0.41)$ \\
DZM $(994)$ & $0.33(0.26-0.40)$ & $0.53(0.43-0.61)$ & $0.30(0.18-0.41)$ & $0.18(0.09-0.26)$ \\
MZF $(1,694)$ & $0.45(0.40-0.50)$ & $0.76(0.71-0.79)$ & $0.45(0.38-0.51)$ & $0.36(0.31-0.42)$ \\
DZF $(1,432)$ & $0.49(0.46-0.54)$ & $0.49(0.42-0.56)$ & $0.17(0.09-0.25)$ & $0.26(0.20-0.32)$ \\
DZU $(2,384)$ & $0.42(0.38-0.45)$ & $0.45(0.39-0.51)$ & $0.12(0.04-0.17)$ & $0.21(0.15-0.21)$ \\
\hline Note: MZM = monozygotic males, DZM = dizygotic males, MZF = monozygotic females, DZF = dizygotic females, DZU = dizygotic opposite sex \\
\multicolumn{2}{l}{ twins. }
\end{tabular}

effects involve the same genetic and environmental factors, but with different effect sizes for males and females. Qualitative sex differences involve influences from sex specific genetic and/or environmental latent factors; that is, they imply that different genes and/or environmental factors influence a given trait in males versus females. We, therefore, applied the approach previously described by Neale et al. (2006). Quantitative sex effects were modelled by allowing the path coefficients from the latent genetic effects to differ for males and females, while constraining the genetic and environmental correlation matrices to be equal across gender. In accordance with Neale et al. (2006), qualitative sex-specific effects were modeled by adding to the quantitative sex limitation model a separate set of genetic effects in males. In the event that there are no qualitative sex differences in the genetic influences, the male-specific genetic paths are estimated to be zero, while at the opposite extreme, if there are no overlapping genetic influences in males and females, the path coefficients in the quantitative part of the model are estimated to be zero in males.

From a bivariate model, allowing for both qualitative and quantitative sex differences, it is possible to calculate the magnitude of genetic overlap between the sexes (genetic correlation, $r_{\mathrm{g}}$ ) for each individual phenotype (given that there are qualitative sex differences), and the correlation between the influence of each latent factor (A, C and $\mathrm{E}$ ) on the two phenotypes in each sex (given quantitative sex differences). Further, as genetic correlation is not informative of the extent to which genes account for the phenotypic correlation, it is also of interest to estimate to what degree the phenotypic correlation can be attributed to genetic (bivariate heritability), shared and non-shared environmental influence (Plomin et al., 2008).

We first fit a model allowing for both qualitative and quantitative sex differences and then tested the effect of shared environment by comparing the fit of the full model to one where all C parameters were fixed at zero. Subsequently, we compared the fit of the full model to one including quantitative sex differences only, and to a model without sex differences, following standard model-fitting procedure by testing submodels where selected parameters were fixed to zero.

\section{Results}

\section{Sample Characteristics}

The final sample consisted of 7,710 participants; 4,464 $(57.9 \%)$ were females and the mean age of all participants in 2008 was 36 (range 29-41) years. Of these, $15.6 \%$ had completed compulsory education only (i.e., 9 years). Higher education (college degree or more) was significantly more prevalent among women $(51.5 \%$ vs. $45.1 \%, p<.001)$, but more men than women had completed an upper university degree ( $16.2 \%$ vs. $11.3 \%, p<.001)$. Annual income in 2008 differed significantly between sexes (median income males 455,000 NOK [approx. 54,300 €], females 323,000 NOK [approx. 38,500€], $p<.001$ ).

\section{Polychoric Correlations}

The phenotypic correlation (95\% CI) between education and income was $0.34(0.32-0.39)$ for men and $0.45(0.43-$ 0.48 ) for women. Table 1 displays polychoric correlations for the two phenotypes in the five zygosity groups. For education, cross-twin correlations were high in all zygosity groups, and about $50 \%$ higher in $\mathrm{MZ}$ than in $\mathrm{DZ}$ twin pairs, indicating influences of both genetic and common environmental factors. For income, correlations were about twice as high in $\mathrm{MZ}$ as in DZ pairs, and lower in DZU twins, indicative of genetic but no common environmental influence, and of qualitative sex differences. Cross-twin crosstrait correlations showed an intermediate pattern.

\section{Bivariate Analysis of Education and Income}

The results from the model fitting of the bivariate Cholesky model allowing for both quantitative and qualitative sex differences are given in Table 2. Model 1 allows for both qualitative and quantitative sex differences. Removing the C parameter (Model 2) resulted in significant deterioration in fit. We then restrained the sex differences to include quantitative effects only (Model 3), but this again resulted in a model that fitted the data significantly worse than the full model. All subsequent models were rejected by the chisquare test, and had higher AIC values than the full model. Thus, Model 1 was chosen as the best-fitting model, indicating that the relationship between education and income was influenced by A, C and E, and that the type and magnitude of genetic effects were dependent on sex. The 
TABLE 2

Model Fitting Results: Bivariate Cholesky Model

\begin{tabular}{|c|c|c|c|c|c|c|c|}
\hline Model & $-2 \|$ & $d f$ & $\mathrm{AlC}$ & diff_II & diff_df & $p$-value & AIC rank \\
\hline 1. Qualitative sex limitation ACE & 44820.79 & 15139 & 14542.49 & - & - & - & 1 \\
\hline 2. Qualitative sex limitation $A E$ & 44849.08 & 15144 & 14561.08 & 28.29 & 5 & $<.001$ & 3 \\
\hline 3. Quantitative sex limitation ACE & 44838.92 & 15142 & 14554.92 & 18.13 & 3 & $<.001$ & 2 \\
\hline 4. Quantitative sex limitation $A E$ & 44892.48 & 15147 & 14598.48 & 71.69 & 8 & $<.001$ & 6 \\
\hline 5. Quantitative sex limitation CE & 45069.56 & 15147 & 14775.56 & 248.77 & 8 & $<.001$ & 8 \\
\hline 6. No sex limitation ACE & 44878.13 & 15146 & 14586.13 & 57.34 & 7 & $<.001$ & 4 \\
\hline 7. No sex limitation $A E$ & 44894.57 & 15149 & 14596.57 & 73.78 & 10 & $<.001$ & 5 \\
\hline 8. No sex limitation CE & 45070.63 & 15149 & 14772.63 & 249.84 & 10 & $<.001$ & 7 \\
\hline
\end{tabular}

Note: Best fitting model in bold type. II = log likelihood, $d f=$ degrees of freedom, AIC = Aikake's information criteria.

parameter estimates for the best fitting model are shown in Figure $1(\mathrm{a})-(\mathrm{c})$.

\section{Genetic and Environmental Contributions to Education and Income}

The contribution of genetic, shared and non-shared environmental factors to the phenotypic correlation between education and income were obtained from OpenMX, but can also be calculated using the numbers in Figure 1. In Figure 2(a), these are presented as absolute values, while the bivariate heritability can be estimated by dividing these numbers on the phenotypic correlation. This gives a bivariate heritability of $(0.41 * 0.19)+(0.47 * 0.12 / 0.34)=0.37$ $(95 \%$ CI $0.10-0.62)$ for men and $(0.74 * 0.47) / 0.45)=0.70$ (95\% CI 0.60-0.90) for women. Corresponding estimates for the relative contribution of common environmental factors were $0.50(0.22-0.69)$ for men and $0.13(0.002-0.29)$ for women, and for unique environmental factors $0.15(0.09-$ $0.21)$ for men and $0.11(0.07-0.17)$ for women. As seen from Figure 2(a), the higher phenotypic correlation between education and income for females could largely be explained by a more prominent contribution from genetic factors in females. Shared environmental factors seemed, on the other hand, to be more important in men than in women, although the confidence intervals for the absolute contributions were overlapping (Figure 2(a)).

The genetic correlation ( $95 \% \mathrm{CI}$ ) between education and income was $0.31(0.08-0.52)$ for men and $0.72(0.64-0.85)$ for women. The $\mathrm{C}$ and $\mathrm{E}$ correlations, constrained to be equal for men and women, were estimated to 1.00 (0.55$1.00)$ and $0.15(0.08-0.22)$, respectively.

The relative influence of genetic and environmental factors on education and income retrieved from the bivariate Cholesky model are displayed in Figure 2(b) and (c). The heritability estimate (with 95\% CI) of educational attainment was $\left(0.42^{2}+0.47^{2}\right)=0.40(0.23-0.57)$ for men and $\left(0.74^{2}\right)=0.55(0.40-0.69)$ for women. Corresponding results for income was $0.46(0.25-0.56)$ and $0.42(0.35-0.48)$. The genetic correlations ( $95 \% \mathrm{CI}$ ) between men and women were $0.66(0.22-1.00)$ for educational attainment and 0.38 (0.01-0.75) for income.

\section{Discussion}

In this cohort of young adult Norwegian twins, the correlation between education and income was moderate, and stronger for women than for men. Our best fitting bivariate model included both quantitative and qualitative sex differences in the relative contribution of genetic factors to individual variation in education and income, and to the correlation between the two measures of socio-economic status. Genetic factors seemed to be relatively more important for women than for men in explaining the correlation between the two phenotypes.

The phenotypic correlation between education and income was moderate. When decomposed into genetic and environmental factors (Figure 2(a)), genetic factors accounted for most of the correlation for females, while common environmental factors seemed more important for men. This difference between sexes was also reflected by the much higher genetic correlation between education and income in women $(0.72$ vs. 0.31$)$. Thus, our results indicate that many of the same genetic factors that drive women towards higher education also drives them towards jobs with higher salaries. For men, however, there might be larger discrepancies between genetically influenced traits (such as personality traits or cognitive abilities) promoting higher education versus higher income levels. One might speculate, for instance, that while cognitive abilities might be more important determinators for higher education, certain personality traits (such as those influencing economic risk taking) might be more important for economic achievement.

In our bivariate model, the heritability estimate of educational attainment was higher for women than for men, while the contribution of shared environmental factors showed the inverse pattern (Figure 2(a)). This is in contrast to what has been found in older Norwegian cohorts. Where Heath et al. (1985) found that for men genetic factors became relatively more important over time than shared environment, while this was not the case for women. Thus, in the youngest cohort they included (born 1950-1960), genetic factors were more (and shared environment less) important for educational attainment for men, while the reverse was true for women. Our findings are also inconsistent with 

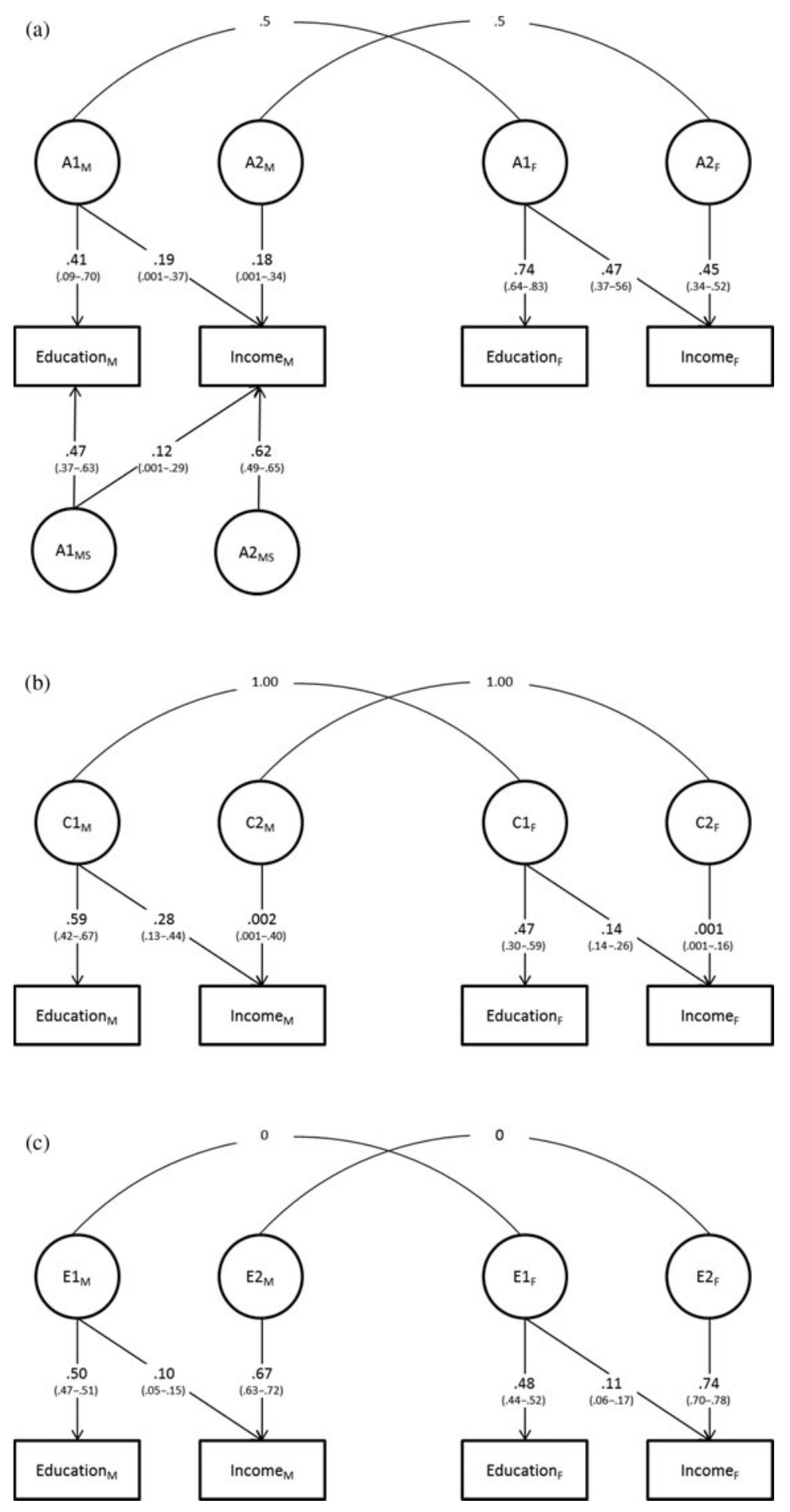

\section{FIGURE 1}

Diagram over the best fitting model (Cholesky ACE with qualitative and qualitative sex limitations) explaining the relationship between educational attainment and income in young adult opposite sex twins. Path estimates for additive genetic (A) (Figure 1(a)), shared environmental (C) (Figure 1(b)) and non-shared environmental (E) (Figure 1(c)) factors, including $95 \%$ confidence intervals. Subscript $F$ indicate female, $M$ indicate male, $M s$ indicate male-specific. Correlation between $A_{M}$ and $A_{F}$ is fixed to 0.5 , correlation between $C_{M}$ and $C_{F}$ fixed to 1.0. (Neale et al., 2006). 


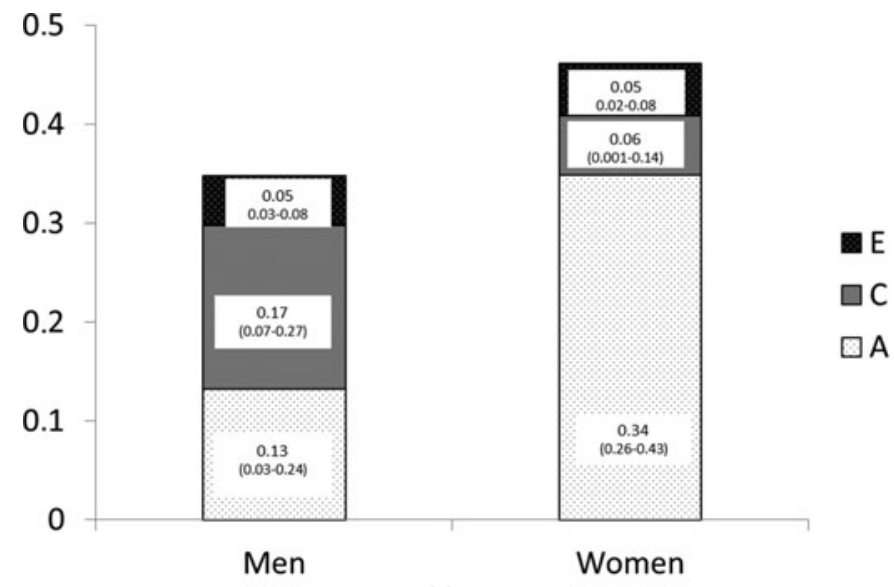

(a)

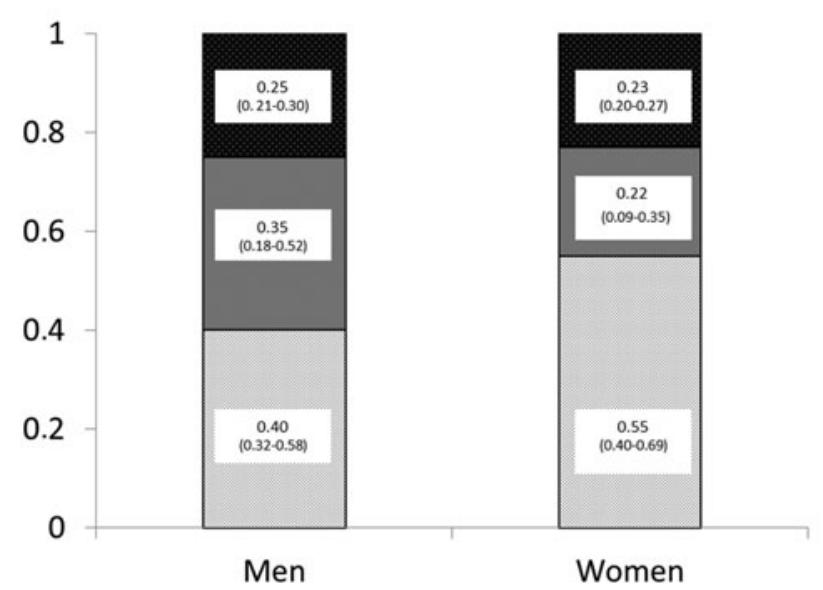

(b)

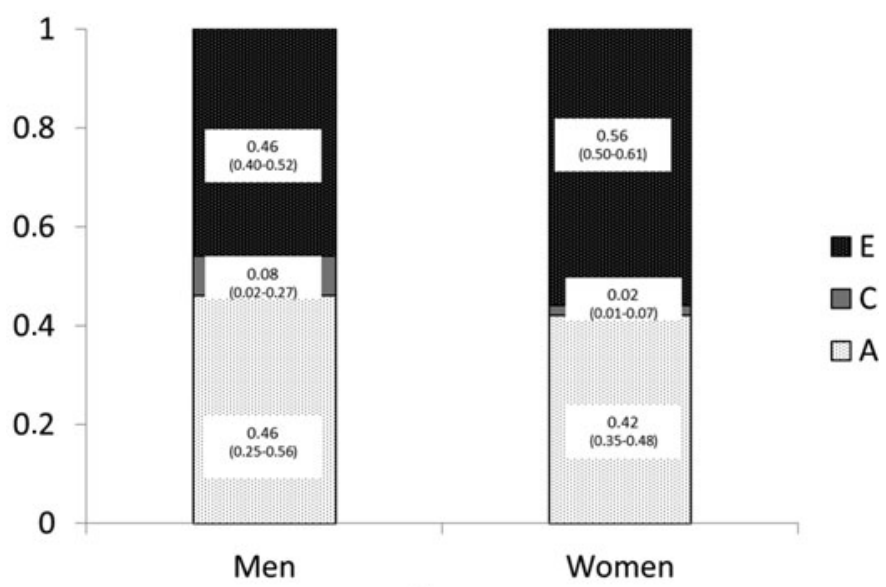

(c)

\section{FIGURE 2}

Relative contributions of additive (A), shared environmental (C) and unique environmental $(E)$ factors for the phenotypic correlation between education and income (Figure 1(a)), and for educational attainment (Figure 1(b)) and income (Figure 1(c)) retrieved from the bivariate Cholesky model.

what is most commonly found worldwide — that genes are relatively more important for men than for women (Branigan et al., 2013). Our heritability estimates for educational attainment had, however, overlapping confidence intervals, and the $95 \%$ CI for the genetic correlation between sexes included 1 . This indicates substantial statistical uncertainty with regard to both quantitative and qualitative sex differences in genetic contributions to educational attainment, 
and thus these results should be interpreted with caution. Moreover, in univariate analyses of educational attainment conducted in a study based on mainly the same sample (on the bivariate relationship between education and anxiety (Tambs et al., 2012)), an ACE model with no sex differences fitted the data best. On the other hand, we at least found no indication of genetic factors being more important for men than for women with regard to educational attainment. This probably is the direct result of the substantial efforts that have been made to provide equal gender opportunities, especially focusing on equal rights to higher education. It is probably also of importance that parental social influence on their children's education might have decreased after the beginning of the 1970s as a consequence of financial aid for students becoming independent of family income. It should also be noted that even though educational levels are very similar between men and women in Norway, area of subjects differ greatly. One can speculate that genes influencing different phenotypes - for example, different personality characteristics - again influence different choices of education in men and women. Sex differences found in this investigation should, however, be confirmed in other studies before any firm conclusions are made.

Our results indicate that common environmental factors are of very limited importance in explaining variation in income levels (Figure 2(b)). We found that genetic factors seemed to be similar in magnitude for men and women, but that genes influencing income levels differed between the sexes. The latter was confirmed in a relatively modest genetic correlation between genetic factors influencing income levels in men and women (0.38). These results are interesting in light of previous studies, although most of these differ slightly in their methodological approach (Benjamin et al., 2012; Björklund \& Jäntti, 2009). Analyses from Sweden, the United States and Australia have revealed heritability estimates ranging from 0.20 to 0.68 , and, with a few exceptions, showed no evidence for common environmental effects (for a review, see Table 1 in Hyytinen et al., 2013). Our twin correlations and heritability estimates correspond closely with those obtained from Swedish samples (Benjamin et al., 2012; Hyytinen et al., 2013), even though these were based on average income over up to 20 years. In their 2006 paper, Miller et al. (2006) reported crosstwin correlation estimates for income in $\mathrm{MZ}$ and DZ twins (Table 2, p. 576) as 0.50 and 0.136 , respectively. Although they do not separate between genders, this is broadly in accordance with our own results (Table 1, column 4), with substantial differences between MZs and DZs in all groups.

Our hypothesis was that genetic (and environmental) factors accounting for income are not necessarily the same across gender, or as those influencing educational level. Qualitative sex differences have, to the best of our knowledge, not been reported previously. Income and wealth are influenced by a large number of factors, of which many are subjected to genetic influence. Economic risk taking has been shown to be influenced by genetic factors, although without detectable gender differences (Le et al., 2010). Other genetically influenced factors, such as personality, might account for our observed gender differences (e.g., so that personality traits influencing economic risk taking, choice of profession, and priorities related to working hours and salary differ between men and women).

\section{Strengths and Limitations}

The strengths of this study are that it is population based, includes all five zygosity groups, and that zygosity was determined using advanced methodology, including DNA analyses. Perhaps most importantly, education and income were measured using public records with high levels of accuracy. The results should, however, be interpreted in light of several limitations. First, although we included a large number of twins, substantial attrition was observed in this sample. As previously reported, cooperation was predicted by monozygosity, female sex and higher education (Tambs et al., 2009). Thus, the twins included in this study had higher mean education than the population means: In the terms used by Statistics Norway, categorizing the population in four categories (1-4), mean level in our sample was 2.46 (95\% CI 2.44-2.49), compared to 2.36 in the general population. It is, however, reassuring that the correlation between education and income corresponded with what has been found for population-representative samples (Aaltonen et al., 2010; Bhuller et al., 2010). Second, income was measured for one year only, and not for a longer period. We chose to measure income for the latest year available instead of a longer period, as our sample was young adults and we, thus, reasoned that the latest year would be more representative of lifetime income. Third, one of the basic presumptions of the classical twin model is that mating is independent of the phenotype under study. A non-random, positive correlation will lead to deflated heritability estimates, as DZ twins will share more than $50 \%$ of the involved genes. There is a well-known spouse correlation for socio-economic factors, especially education (Tambs \& Moum, 1992). In the current study, we did not adjust for this as data were not available for parents' income levels. We, therefore, must assume that the heritability estimates found in this study were lower and the contribution of common environment higher than if this had been taken into consideration. Fourth, we were not able to adjust for gene-environment correlation or geneenvironment interaction. Fifth, the results are probably not universal but restricted to nations with high levels of gender equality such as the Nordic countries.

\section{Conclusion}

In Norway, a relatively egalitarian society, genetic and environmental contribution to the correlation between educational attainment and income differs between men and women. Thus, genetic as well as environmental factors seem important to explain the gender gap in returns 
to education and to economic achievement in general. Further studies should be conducted to explore whether these results are applicable in other countries, as well as studies directed towards understanding underlying genetically (as well as environmentally) influenced characteristics, such as personality, and include occupation/trades as well as academic achievement.

\section{Acknowledgments}

The work was supported by grants from the Norwegian Research Council. Data on zygosity on the twins used in this study was obtained from the Norwegian Twin Registry, the Norwegian Institute of Public Health. The work was also in part supported by NIH grant $\mathrm{MH}-068643$. We are very grateful to the twins for their participation.

\section{References}

Aaltonen, S., Ortega-Alonso, A., Kujala, U. M., \& Kaprio, J. (2010). A longitudinal study on genetic and environmental influences on leisure time physical activity in the Finnish Twin Cohort. Twin Research and Human Genetics, 13, 475481.

Adler, N. E., \& Ostrove, J. M. (1999). Socioeconomic status and health: What we know and what we don't. New York Academy of Sciences, 896, 3-15.

Akaike, H. (1987). Factor-analysis and AIC. Psychometrica, 52, 317-332.

Benjamin, D. J., Cesarini, D., Chabris, C. F., Glaeser, E. L., Laibson, D. I., Guethnason, V., ... Lichtenstein, P. (2012). The promises and pitfalls of genoeconomics. Annual Review of Economics, 4, 627-662.

Bhuller, M., Mogstad, M., \& Salvanes, K. G. (2010). Life-cycle bias and the returns to schooling in current and lifetime earnings (IZA Discussion Paper Series No. 5788). St Louis, MO: Research Division of Federal Reserve Bank of St Louis.

Bjorklund, A., Eriksson, T., Jantti, M., Raaum, O., \& Osterbacka, E. (2002). Brother correlations in earnings in Denmark, Finland, Norway and Sweden compared to the United States. Journal of Population Economics, 15, 757-772.

Björklund, A., \& Jäntti, M. (2009). Intergenerational income mobility and the role of family background. In W. Salverda, B. Nolan \& T. M. Smeeding (Eds.), The Oxford handbook of economic inequality (pp. 491-521). Oxford: Oxford University Press.

Boker, S., Neale, M. C., Maes, H., Wilde, M., Spiegel, M., Brick, T., ... Fox, J. (2011). OpenMx: An Open source extended structural equation modeling framework. Psychometrica, 76, 306-317.

Bonjour, D., Cherkas, L., Haskel, J., Hawkes, D., \& Spector, T. (2002). Returns to education: Evidence from UK twins. London: Center for the Economics of Education, London School of Economics and Political Science.

Branigan, A. R., McCallum, K. J., \& Freese, J. (2013). Variation in the heritability of educational attainment: An international meta-analysis. Social Forces, 92, 109-140.
Bratberg, E., Nilsen, O. A., \& Vaage, K. (2005). Intergenerational earnings mobility in Norway: Levels and trends. Scandinavian Journal of Economics, 107, 419-435.

Ermisch, J. \& Francesconi, M. (2001). Family matters: Impacts of family background on educational attainments. Economica, 68, 137-156.

European Commission. (2013). The situation in EU. Brussel: Author.

Harris, J. R., Magnus, P., \& Tambs, K. (2006). The Norwegian Institute of Public Health twin program of research: An update. Twin Research and Human Genetics, 9, 858864.

Heath, A. C., Berg, K., Eaves, L. J., Solaas, M. H., Corey, L. A., Sundet, J., ... Nance, W.E. (1985). Education policy and the heritability of educational attainment. Nature, 314, 734736.

Hirsch, A., Flatebø, G., Modig, I., Sandnes, T., Aalandslid, V., Thorsen, L. R., ... Stene, R. J. (2010). Women and men in Norway. Oslo: Statistics Norway.

Hyytinen, A., Ilmakunnas, P., Johansson, E., \& Toivanen, O. (2013). Heritability of Lifetime Income (MPRA paper no. 46326). Helsinki: Helsinki Center of Economic Research.

Johnson, W., Deary, I. J., Silventoinen, K., Tynelius, P., \& Rasmussen, F. (2010). Family background buys an education in Minnesota but not in Sweden. Psychological Sciences, 21, 1266-1273.

Le, A. T., Miller, P. W., Slutske, W. S., \& Martin, N. G. (2010). Are attitudes towards economic risk heritable? Analyses using the Australian twin study of gambling. Twin Research and Human Genetics, 13, 330-339.

Lindahl, L. (2011). A comparison of family and neighborhood effects on grades, test scores, educational attainment and income-evidence from Sweden. Journal of Economic Inequality, 9, 207-226.

Lynch, S. M. (2006). Explaining life course and cohort variation in the relationship between education and health: the role of income. Journal of Health and Social Behavior, 47, 324-338.

Magnus, P., Berg, K., \& Nance, W. E. (1983). Predicting zygosity in Norwegian twin pairs born 1915-1960. Clinical Genetics, 24, 103-112.

Miller, P., Mulvey, C., \& Martin, N. (1996). Earnings and schooling: an overview of economic research based on the Australian Twin Register. Acta Geneticae Medicae et Gemellologiae, 45, 417-429.

Miller, P., Mulvey, C., \& Martin, N. (1999). Genetic and environmental contribution to educational attinament in Australia. Economics of Education Review, 20, 211-224.

Miller, P., Mulvey, C., \& Martin, N. (2006). The return to schooling: Estimates from a sample of young Australian twins. Labour Economics, 13, 571-587.

Neale, M. C., \& Cardon, L. R. (1992). Methodology for genetic studies of twins and families. Dordrecht, the Netherlands: Kluwer.

Neale, M. C., Roysamb, E., \& Jacobson, K. (2006). Multivariate genetic analysis of sex limitation and $\mathrm{G} x$ E interaction. Twin Research and Human Genetics, 9, 481-489. 
Nilsen, T. S., Brandt, I., Magnus, P., \& Harris, J. R. (2012). The Norwegian Twin Registry. Twin Research and Human Genetics, 15, 775-780.

Nilsen, T. S., Knudsen, G. P., Gervin, K., Brandt, I., Roysamb, E., Tambs, K., ... Harris, J.R. (2012). The Norwegian Twin Registry from a public health perspective: A research update. Twin Research and Human Genetics, 15, 1-11.

OECD. (2011). Education at a glance 2011: OECD indicators. OECD Publishing. Retrieved from http://dx.doi.org/10.1787/eag-2011-en

Plomin, R., DeFries, J. C., McClearn, G. E., \& McGuffin, P. (2008). Behavioral genetics (5th ed.). New York: Worth Publishers.

Rognerud, M. A., \& Zahl, P. H. (2006). Social inequalities in mortality: changes in the relative importance of income, education and household size over a 27 -year period. European Journal of Public Health, 16, 62-68.

Saeter, J. P. (2009). Social inheritance - Education, occupation and standards of living [In Norwegian] (Report No. 16). Oslo: Statistics Norway.

Skrede, K. (2010). Economical analyses 5/2010 [In Norwegian]. Oslo: Statistics Norway.
Szanton, S. L., Johnson, B., Thorpe, R. J., \& Whitfield, K. (2009). Education in time: Cohort differences in educational attainment in African-American twins. PLoS One, 4, e7664.

Tambs, K., Kendler, K. S., Reichborn-Kjennerud, T., Aggen, S. H., Harris, J. R., Neale, M. C., ... Røysamb, E. (2012). Genetic and environmental contributions to the relationship between education and anxiety disorders - A twin study. Acta Psychiatrica Scandinavica, 125, 203-212.

Tambs, K., \& Moum, T. (1992). No large convergence during marriage for health, lifestyle, and personality in a large sample of Norwegian spouses. Journal of Marriage and Family, 54, 957-71.

Tambs, K., Ronning, T., Prescott, C. A., Kendler, K. S., Reichborn-Kjennerud, T., Torgersen, S., ... Harris, J. R. (2009). The Norwegian institute of public health twin study of mental health: Examining recruitment and attrition bias. Twin Research and Human Genetics, 12, 158-168.

Tambs, K., Sundet, J. M., Magnus, P., \& Berg, K. (1989). Genetic and environmental contributions to the covariance between occupational status, educational attainment, and IQ: A study of twins. Behavior Genetics, 19, 209-222. 